\title{
CONTROL OF WATER CONSUMPTION BY THE OLIVE TREE
}

\author{
J. E. Fernández, F. Moreno, I. F. Girón, and O. M. Blázquez \\ Instituto de Recursos Naturales y Agrobiología (CSIC) \\ P.O. Box 1052, 41080-Sevilla, Spain
}

\begin{abstract}
$\underline{\text { Abstract }}$
Measurements of leaf water potential $(\Psi)$ and stomatal conductance to $\mathrm{H}_{2} \mathrm{O}(\mathrm{g})$ were made in 26-year-old Manzanillo olive trees under irrigation and dry-farming conditions. On days of high water demand, the olive trees reduced water losses by closing the stomata, so preventing excessive water stress. The analysis of $g$ values versus photosynthetically active radiation $\left(\mathrm{I}_{\mathrm{PAR}}\right)$ and vapour pressure deficit (VPD), showed that stomata were fully opened at relatively low $\mathrm{I}_{\mathrm{PAR}}$ levels, from about $500 \mu \mathrm{mol} \mathrm{m} \mathrm{m}^{-2} \mathrm{~s}^{-1}$. Also, $g$ decreased with increasing VPD, for values of up to approximately $4 \mathrm{kPa}$. After plotting the relative extractable soil water (REW) values against their counterparts of pre-dawn leaf water potential $\left(\Psi_{\mathrm{pd}}\right)$, it was observed that $\Psi_{\mathrm{pd}}$ remained constant for values of REW higher than 0.4 , with a mean value of $-0.46 \mathrm{MPa}$.
\end{abstract}

Additional index words: Olea europaea, irrigation, stomata, leaf water relations.

\section{Introduction}

The good adaptation of the olive tree (Olea europaea L.) to dry conditions is well known. Some mechanisms and features involved in its tolerance to or avoidance of water stress are described in the literature. Leon and Bukovac (1978), Bongi et al. (1987a, 1987b) and Cowling and Campbell (1983) described various xerophytic characteristics of the olive leaf. Abd-El-Rahman et al. (1966) and Rieger (1995) observed osmotic adjustment that helped the plant to withstand dry conditions. The role of the olive roots in the adaptation to dry conditions has been observed by Fernández et al., (1994), and Moreno et al. (1996) described some features of the hydraulic functioning under different soil water conditions. The low hydraulic conductivity of the olive xylem (Salleo et al., 1985; Larsen et al., 1989; Rieger, 1995) seems to be one of the features responsible for the reduced water consumption in the olive tree (Lo Gullo and Salleo, 1988; Larsen et al., 1989). Larsen et al., 1989 observed in stressed olive trees a quick recovery of the leaf water potential after the central hours of the day, which they attribute to stomatal closing.

In this work, leaf water relations were studied in 26-year-old olive trees under irrigation and under dry-farming conditions, with the aim of identifying mechanisms for the control of the water used by the olive tree. 
The experiments were carried out in an one ha orchard of 26-year-old olive trees (Olea europaea L., var. Manzanillo) planted at $7 \times 7 \mathrm{~m}$, belonging to the Institute for Natural Resources and Agrobiology, near Seville in Spain ( $37^{\circ} 17^{\prime} \mathrm{N}, 6^{\circ} 3^{\prime} \mathrm{W}$, elevation $30 \mathrm{~m}$ ). The soil is a sandy loam of about $2 \mathrm{~m}$ depth, with $27.5 \%$ coarse sand, $36.5 \%$ fine sand, $13.4 \%$ silt and $22.6 \%$ clay. The volumetric soil water content at the upper limit of the field capacity is $0.33 \mathrm{~m}^{3} \mathrm{~m}^{-3}$, and the lower limit of the wilting point is 0.10 $\mathrm{m}^{3} \mathrm{~m}^{-3}$. Two water regimes were imposed, in three representative trees per treatment. The first treatment (I) consisted of weekly irrigation to cover the crop water demand $\left(\mathrm{ET}_{\mathrm{c}}\right)$ calculated by the equation:

$$
\mathrm{ET}_{\mathrm{c}}=\mathrm{K}_{\mathrm{r}} \mathrm{K}_{\mathrm{c}} \mathrm{Et}_{\mathrm{o}}
$$

where $\mathrm{K}_{\mathrm{r}}$ is the coefficient relating the percent shaded area of the orchard floor and $\mathrm{ET}_{\mathrm{c}}$ (Fereres and Castel, 1981), $\mathrm{K}_{\mathrm{c}}$ is the crop coefficient given by Pastor (1994), and $\mathrm{ET}_{\mathrm{o}}$ is the potential evapotranspiration calculated by the FAO-Penman equation. Irrigation was carried out from the middle of March 1995 (day of the year, DOY 77) to the middle of September (DOY 262). The water was applied in a $2.5 \mathrm{~m}$ radius pond around each tree. The second treatment (D) was dry-farming conditions.

The experimental period was unusually dry, with only $79 \mathrm{~mm}$ of rainfall between March and September. Soil water status was monitored in one tree per treatment, with a maximum frequency of 15 days and always on the days in which plant measurements were made. Measurements of volumetric soil water content $(\theta)$ were made from $0.2 \mathrm{~m}$ down to $1.5 \mathrm{~m}$, every $0.1 \mathrm{~m}$, with a neutron probe (Troxler 3300) in access tubes installed at $0.5,1.5$ and $2.5 \mathrm{~m}$ from the trunk. For the top layer of the soil, $\theta$ was measured by time-domain-reflectometry (Tektronix 1502C). The wave-forms were analysed similarly to as described by Baker and Allmaras (1990). Soil moisture profiles were used to calculate a depth equivalent of water, expressed here as the level of relative extractable water (REW) by the equation (Bréda et al., 1995a,b):

$$
\mathrm{REW}=\left(\mathrm{R}-\mathrm{R}_{\min }\right) /\left(\mathrm{R}_{\max }-\mathrm{R}_{\min }\right)
$$

where $\mathrm{R}$ is the actual soil water content, $\mathrm{R}_{\min }$ the minimum measured soil water content, and $R_{\max }$ the soil water content at field capacity. Total soil extractable water $\left(R_{\max }-R_{\min }\right)$ was $306 \mathrm{~mm}$. The soil matric potential (h) was measured by two mercury tensiometers installed at 0.45 and $0.90 \mathrm{~m}$ depth, $1.5 \mathrm{~m}$ from the trunk. The retention curve determined by Moreno et al. (1996) in the experimental orchard was used to calculate the $h$ values from the $\theta$ measurements. The soil of treatment I showed $h$ values higher than $-0.05 \mathrm{MPa}$ throughout the experimental period, with values around $-0.03 \mathrm{MPa}$ most of the time. In the unirrigated treatment, $h$ values were very low for most of the experimental period, due to the lack of rain, and were lower than $-1.5 \mathrm{MPa}$ at the end of the dry season.

Leaf water potential $(\Psi)$ and stomatal conductance to $\mathrm{H}_{2} \mathrm{O}(\mathrm{g})$ were measured on leaves from the year, healthy and in sunny positions. A pressure chamber (Soilmoisture Equipment Corp, USA) was used for the measurements of $\Psi$. Measurements of $g$ were made on the abaxial surface of leaves, with a steady-state porometer (LI-1600, LI-COR, USA). Diurnal evolutions of both parameters were monitored in April, July and September, with measurements every 2.5 hours from dawn to sunset. Two leaves were sampled from each experimental tree, on three trees per treatment, at $1.6-1.9 \mathrm{~m}$ above 
soil level. In April and July, measurements were carried out the first and third days after irrigation, to check the influence of soil drying. In September, measurements were made six days after irrigation.

Climatic parameters were measured at the experimental farm with an automatic weather station, recording thirty-minute averages of global solar radiation, photosynthetically active radiation $\left(\mathrm{I}_{\mathrm{PAR}}\right)$, wind speed, rainfall, and air temperature and humidity. The values of $I_{\mathrm{PAR}}$ measured by the sensor of the porometer were used in the analysis of the stomatal conductance response versus incident radiation, to be sure that radiation was measured at the same angle as the leaf.

\section{Results and discussion}

The daily curves of $\Psi$ and g observed on the measurement days throughout the experimental period are shown in Figure 1. In April, no significant differences between

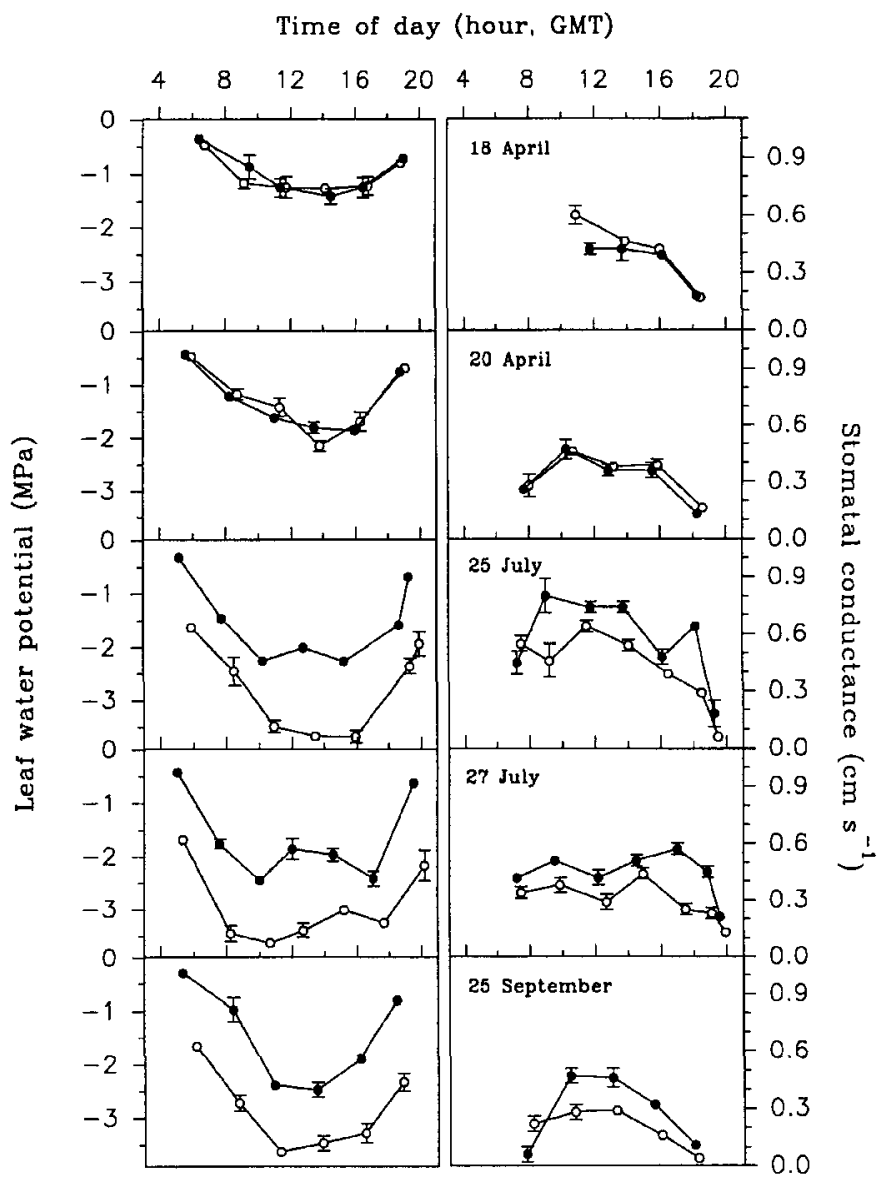

Figure 1. Diurnal variations of leaf water potential and stomatal conductance in irrigated $(\bullet)$ and unirrigated $(0)$ trees. The vertical bars represent $\pm S E(n=6)$. 
treatments were observed in either parameter, in general, but big differences were found in July and September. This agrees with the soil water content measured in each treatment. Figure 2 shows that in April, the soil water content in the unirrigated trees was enough to prevent significant water stress. We assumed an REW threshold for soil water deficit of 0.4 , after plotting REW versus predawn leaf water potential $\left(\Psi_{\mathrm{pd}}\right)$, used as indicator of water stress (Fig. 3). The mean value of $\Psi_{\text {pd }}$ for $R E W \geq 0.4$ was -0.46 $\mathrm{MPa}$. In July and September, however, REW values in the unirrigated trees were very low (Fig. 2).

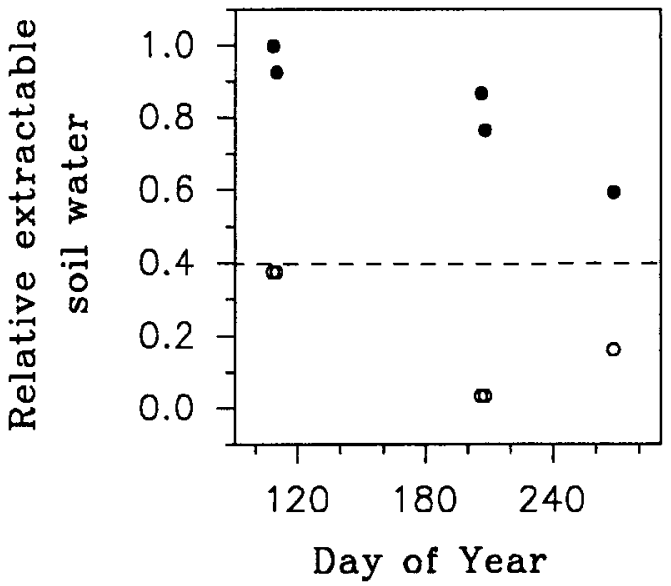

Figure 2. Relative extractable soil water (REW) for the irrigated $(\bullet)$ and unirrigated treatments (o). Data are the average of three measurements. The dotted line indicates the value of REW considered to be the water deficit threshold.

Relative extractable soil water

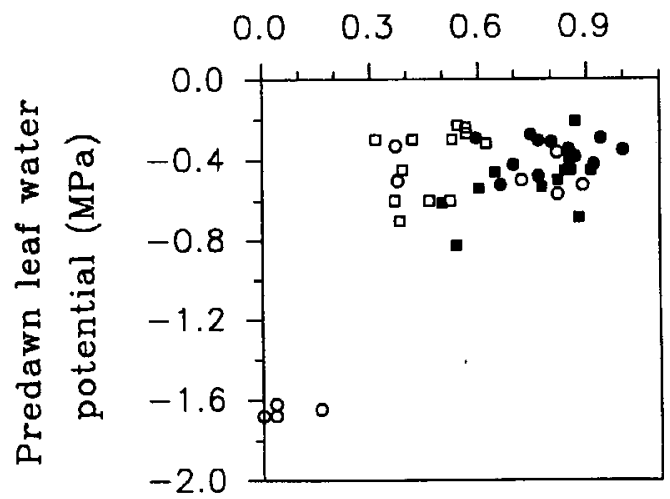

Figure 3. Relative extractable soil water versus water predawn leaf water potential. Data are from irrigated $(\bullet)$ and unirrigated (o) trees. Data obtained by Fernandez (1989) in the same orchard (- irrigated trees; $\square$ unirrigated trees) have also been used. Each value is the average of three volumetric soil water content measurements and six leaf water potential measurements. 
On the 25th of July, the values of $\Psi$ decreased from sunrise until late in the afternoon. On the 27th, however, minimum values of $\Psi$ were reached before midday, and then remained more or less constant until late in the afternoon. The daily trends of $\mathrm{g}$ were also different on both days, and lower values were found on the 27 th than on the 25 th, for both treatments. Figure 4 shows that the atmospheric water demand was much higher on the 27 th than on the 25 th.

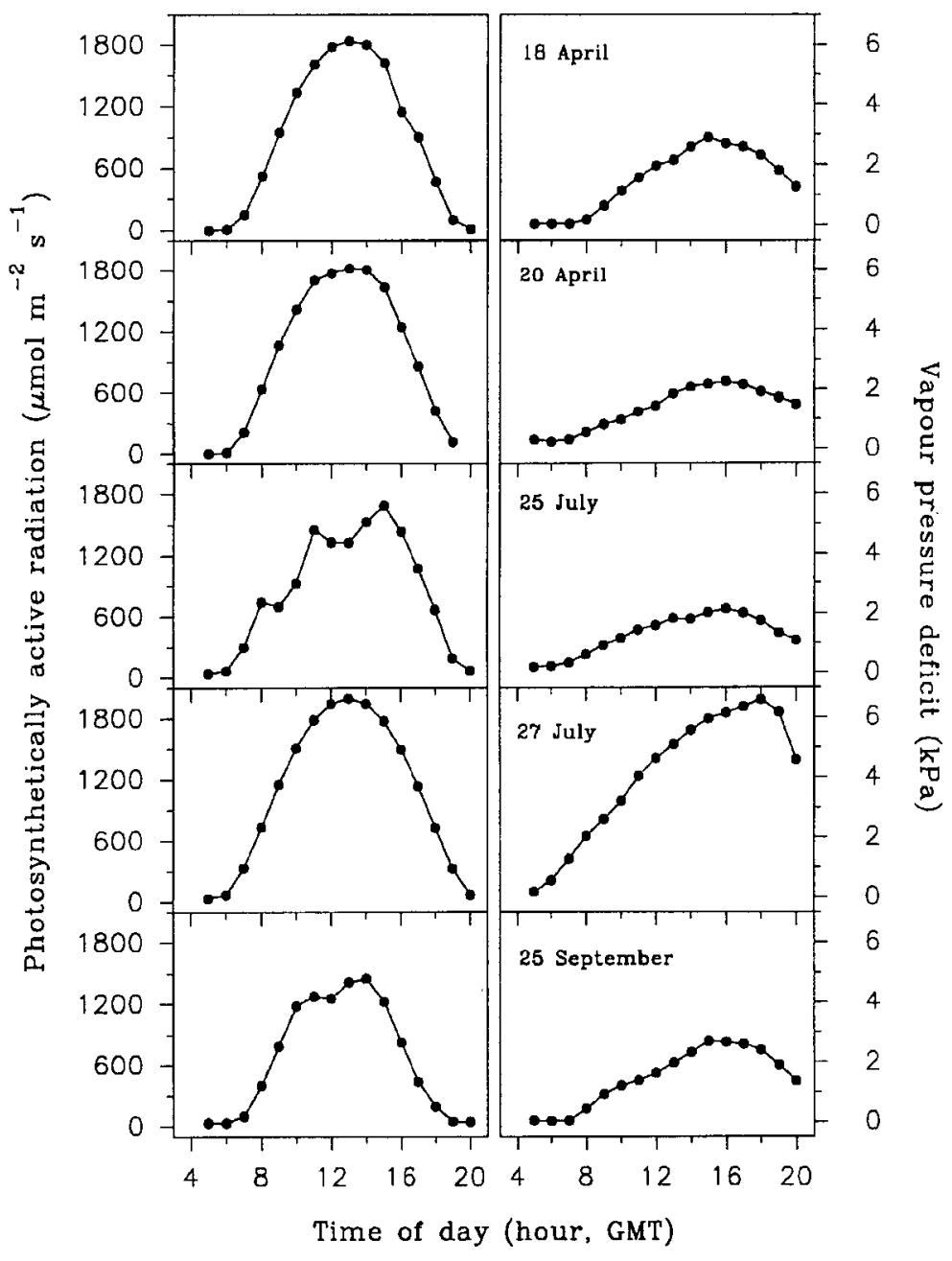

Figure 4. Diurnal variations of photosynthetically active radiation and vapour pressure deficit measured at the experimental farm.

In Figure 5, values of $g$ for both treatments have been plotted with their counterparts of $I_{P A R}$ (Fig. 5a) and Vapour pressure deficit (VPD) (Fig. 5b). High values of $g$ were observed at relatively low radiation, from about $500 \mu \mathrm{mol} \mathrm{m} \mathrm{m}^{-2} \mathrm{~s}^{-1}$. A proportional decrease in $\mathrm{g}$ was found with increasing VPD, for VPD values of up to approximately 4 $\mathrm{kPa}$. 
Photosynthetically active radiation $\left(\mu \mathrm{mol} \mathrm{m} \mathrm{m}^{-2} \mathrm{~s}^{-1}\right)$

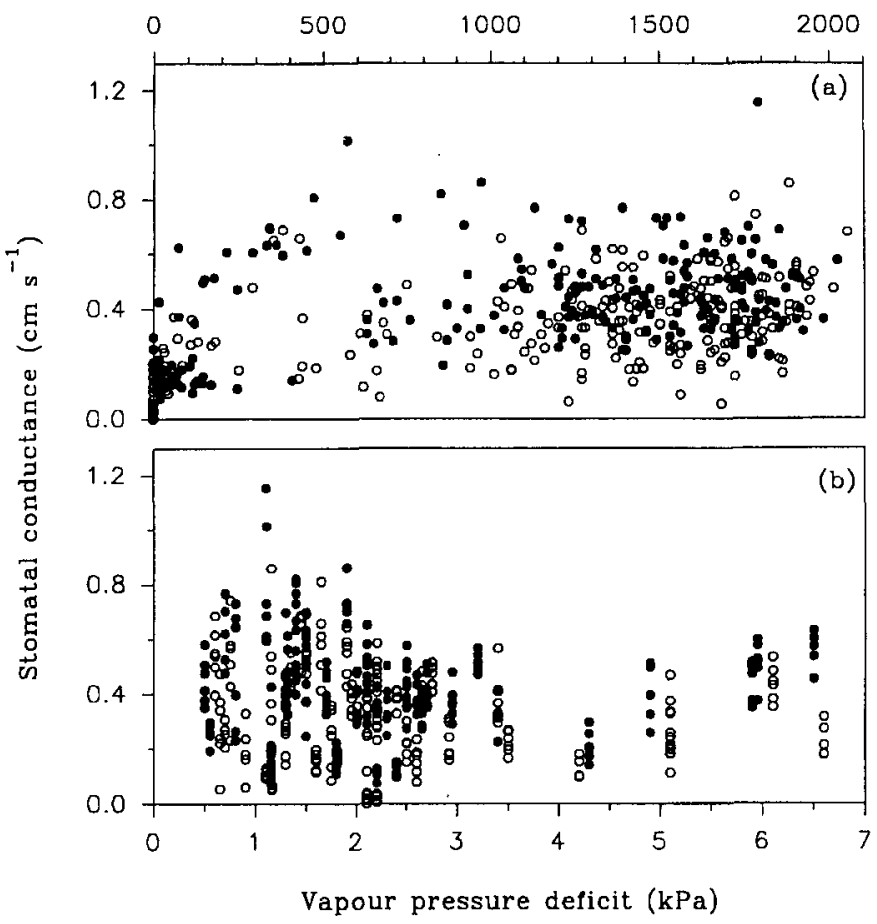

Figure 5. Stomatal conductance vs photosynthetically active radiation (a) and vapour pressure deficit (b) for leaves of the irrigated $(\bullet)$ and unirrigated (o) trees.

For the olive tree, the REW value of 0.4 can be assumed as the soil water deficit threshold. This agrees with the value found for other tree species (Bréda et al., 1995). Measurements of $\Psi$ and $g$ made in July show that the olive tree is able to restrict water loss by closing the stomata. On the 27th, a day of high water demand, the trees closed stomata early in the morning, preventing an excessive drop in $\Psi$. This agrees with the findings of Larsen et al. (1989) in Nabali olive trees, though the diurnal patterns of $\Psi$ and $\mathrm{g}$ observed in this variety were different from those found in Manzanillo variety. The fact that the g values measured on the 27th were lower than on the 25th, even in the unirrigated trees where no appreciable change in REW was detected between the two measurement days (Fig. 2), indicates that the decrease in $g$ must be due in part to stomatal closure and not only to the low hydraulic conductance of the xylem, as observed by Lo Gullo and Salleo (1989) in wild olive trees.

The marked response of $g$ to the increase in $I_{P A R}$, from 0 to about $200 \mu \mathrm{mol} \mathrm{m}^{-2} \mathrm{~s}^{-1}$, explains the high values of $\mathrm{g}$ observed early in the morning. Also, the decrease of $\mathrm{g}$ from midday may be the consequence of the stomatal closure as VPD increases.

Acknowledgements: We thank J. Rodriguez and J.P. Calero for their help with field measurements. This study was supported with funds of the Junta de Andalucía (Research Group 2042). 


\section{$\underline{\text { References }}$}

Abd-El-Rahman, A.A., Shalaby, A.F., and Balegh, M., 1966. Water economy of olive under desert conditions. Flora 156:202-219.

Baker, J.M. and Allmaras, R.R., 1990. System for automating and multiplexing soil moisture measurements by time-domain reflectometry. Soil Sci. Soc. Am. J. 54:1-6

Bongi, G., Mencuccini, M., and Fontanazza, G., 1987a. Photosynthesis of olive leaves: Effect of light flux density, leaf age, temperature, peltates, and $\mathrm{H}_{2} \mathrm{O}$ vapor pressure deficit on gas exchange. J Amer. Soc. Hort. Sci 112(1):143-148.

Bongi, G., Soldatini, G.F., and Hubick, K.T., 1987b. Mechanism of photosynthesis in olive tree (Olea europaea L.). Photosynthetica 21(4):572-578.

Bréda, N., Granier, A., and Aussenac, G., 1995a. Effects of thinning on soil and tree water relations, transpiration and growth in an oak forest (Quercus petraea (Matt.) Liebl.). Tree Physiol. 15:295-306.

Bréda, N., Granier, A., Barataud, F., and Moyne, C., 1995b. Soil water dynamics in an oak stand. Plant and Soil 172:17-27.

Cowling, R.M. and Campbell, B.M., 1983. The definition of leaf consistence categories in the fynbos biome and their distribution along an altitudinal gradient in South eastern Cape. J.of S. African Bot. 49:87-101.

Fereres, E. and Castel, J.R., 1981. Drip irrigation management. Division of Agricultural Sciences, University of California. Leaflet 21259.

Fernández, J.E., 1989. Comportamiento del olivo (Olea europaea L., var. Manzanillo) sometido a distintos regímenes hídricos, con especial referencia a la dinámica del sistema radicular y de la transpiración. Ph.D. Thesis, Department of Agronomy, University of Córdoba, Spain, $271 \mathrm{pp}$.

Fernández, J.E., Moreno, M., Martín-Aranda, M.J., and Rapoport, H.F., 1994. Anatomical response of olive roots to dry and irrigated soils. Adv. Hort. Sci. 8:141144.

Larsen, F.E., Higgins, S.S., and Al Wir, A., 1989. Diurnal water relations of apple, apricot, grape, olive and peach in an arid environment (Jordan). Sci. Hortic. 39:211222.

Leon, J.M. and Bukovac, M.J., 1978. Cuticle development and surface morphology of olive leaves with reference to penetration of foliar-applied chemicals. J. Amer. Soc. Hort. Sci. 103(4):465-472.

Lo Gullo, M.A. and Salleo, S., 1988. Different strategies of drought resistance in three Mediterranean sclerophyllous trees growing in the same environmental conditions. New Phyt. 108:267-276.

Moreno, F., Fernández, J.E., Clothier, B.E., and Green, S.R., 1996. Transpiration and root water uptake by olive trees. Plant and Soil. (in press).

Pastor, M. and Orgaz, F., 1994. Riego deficitario del olivar. Agricultura 746:768-776.

Rieger, M., 1995. Offsetting effects of reduced root hydraulic conductivity and osmotic adjustment following drought. Tree Physiol. 15:379-385.

Salleo, S., Lo Gullo, M.A., and Oliveri, F., 1985. Hydraulic parameters measured in 1year- old twigs of some Mediterranean species with diffuse-porous wood: Changes in hydraulic conductivity and their possible functional significance. J. exp. Bot. $36: 1-11$. 